\title{
URGENSI MATERI PEMBELAJARAN AKHLAK K.H. HASYIM ASY'ARI DALAM MENGHADAPI TANTANGAN PEMBELAJARAN ABAD 21
}

\author{
Ahmad Dwi Nur Khalim \\ Universitas Mercu Buana Yogyakarta \\ Email; ahmadkhalim55@gmail.com
}

\begin{abstract}
: 21st century learning discourse is getting bigger in the current global world. All countries are competing to prepare the best possible human resources. It's just that if not accompanied by morals will backfire for the country. This study aims to look at the urgency of the moral learning material of ideas from K.H. Hasyim Asy'ari in welcoming 21st century learning. This research is library research. The data source is obtained from the book of adab al-'alim wa al-muta'alim. Methods of data analysis using descriptive methods, the data obtained by documentation techniques. Then the descriptive data are analyzed deeper using content analysis. The results showed that in the book of adab al-'alim wa al-muta'alim by K.H. Hasyim Asy'ari has education significance, ethics that students must possess (ethics in learning, ethics towards teachers, ethics towards subjects, ethics that must be possessed by teachers (teacher ethics, teacher ethics in teaching, teacher ethics to students, ethics towards books and learning media). While the urgency is clearly seen that the moral teaching material of K.H. Hasyim Asy'ari to directs close to Allah. hen with the moral teaching material K.H. Hasyim Asy'ari can equip characters in multiple dimension. And with these materials students can have a foundation of integrity in life.
\end{abstract}

Keywords: Urgency, Learning, K.H. Hashim Asy'ari, 21st Century

\section{PENDAHULUAN}

Pembelajaran Abad 21 sudah mulai digaungkan. Munculnya wacana pembelajaran abad 21, tak ubahnya menjadi tantangan yang menarik. Diterbitkannya panduan implementasi kecakapan abad 21 pada kurikulum 2013 pada Juni 2017, oleh Ditjen Pendidikan Dasar dan Menengah menambah seriusnya tantangan tersebut.. Tantangan wacana pembelajaran abad 21 memang bukan hal "remeh-temeh", ia lahir karena tuntutan dunia global. Dalam panduan implementasi tersebut ditegaskan bahwa :

"Abad 21 merupakan abad yang belandaskan ilmu pengetahuan dan teknologi, sehingga menuntut sumber daya manusia (SDM) suatu negara untuk menguasai berbagai bentuk keterampilan, termasuk keterampilan berpikir kritis dan pemecahan masalah dari berbagai permasalahan yang semakin meningkat. Dengan kata lain, berbagai keterampilan dalam bingkai ilmu pengetahuan dan teknologi yang perlu dikuasai oleh SDM, menjadi kata kunci bagi sebuah bangsa untuk turut serta dalam percaturan dunia" (Ditjen Pendidikan Dasar dan Menegah :2017)

Panduan Implementasi kecakapan tesebut lahir bukan tanpa alasan. Banyak dari siswa kita yang sampai hari ini masih hidup "easy going" cari enak nya saja bukan cari baiknya bagaimana. Ditambah lagi adanya smartphone, membuat semuanya menjadi lebih mudah. Hanya saja kemudahan disini disalah artikan. Bukan untuk melakukan pekerjaan se-efektif mungkin kemudian lanjut mengerjakan hal yang lain. Tapi justru malah membuat terbenam pada kemalasan. Padahal, dalam kajian parenting sering disampaikan bahwa energi usia pelajar itu lebih-lebih. Al-hasil ketika sudah merampungkan suatu aktivitas, mereka cenderung 
mudah bosan. Setelah bosan tentunya mereka akan mencari hal lain untuk menyalurkan energinya. Namun disayangkan, energi lebih pada diri siswa disalurkan ke aktifitas yang kurang bermanfaat. Bahkan cenderung mengarah pada tindakan tidak bermoral.

Sebagai bukti, sebagaimana dikutip dari tribun-medan.com yang terjadi pada akhir-akhir ini. Dalam berita tersebut dituliskan judul "Siswa SMA Buka Bra di Instagram, Jenuh Banyak PR. KPAI Sebut Ini Bentuk Kebosanan Belajar di Rumah". Dalam artikel berita ini, Komisioner KPAI Bidang Pendidikan Retno Listyarti, melalui konferensi pers online pada Maret lalu menyampaikan bahwa KPAI telah melakukan Survey sebanyak 1.700 responden mulai dari TK sampe jenjang SMA/SMK. Survey ini di laksanakan dengan tujuan untuk melihat presepsi siswa tentang pembelajaran jarak jauh. Dalam survey tersebut dikatakan bahwa karena tingkat kebosenan siswa, akhirnya siswa nyari hal-hal yang menurut mereka lebih asik seperti ikut challenge di aplikasi Tiktok termasuk juga aksi buka baju di live Instagram barubaru ini," (Tribun-Medan.com:2020)

Fakta diatas tentunya hanya satu dari sekian kasus yang hampir serupa. Namun dari fakta tersebut dapat membuka mata kita bahwa dalam pembelajaran abad 21 ini teknologi menjadi urgen. Tetapi teknologi kalau tidak dibarengi dengan akhlak, maka muaranya adalah tindakan negatif. Untuk itu dalam menyambut pembelajaran Abad 21, Indonesia perlu menyiapkan pondasinya. Tentunya harus mulai berbenah dan menyiapkan diri dari semua lini. Jangan sampai dalam percaturan dunia kita hanya sebagai penonton saja. Dan disisi lain sebagai bangsa besar yang menjujung budaya ketimuran, haruslah selalu memupuk etika ketimuran. Agar nantinya bisa seimbang antara kecakapan softskill-hardskill dan perilaku berakhlak.

Sedikit angin segar bagi Bangsa Indonesia. Ketika membicarakan keseimbangan pendidikan dan akhlak, Indonesia memiliki figur-figur tokoh yang bisa menjadi rujukan. Salah satunya yang terbukti pemikirannya telah menembus batas, yakni K.H. Hasyim Asy'ari. Walaupun orang juga mengenal beliau sebagai seorang tokoh sosial-politik yang mengawal kemerdekaan Indonesia. Baik melawan hegemoni kolonial belanda maupun jepang. Namun, sosok K.H. Hasyim Asy'ari hakikatnya merupakan tokoh yang mengembangkan sistem pendidikan warna baru pada zamannya. Walaupun sistem pendidikan baru yang beliau cetuskan, tapi beliau mengusung semangat perenilaisme. Yakni mengambil apa yang baik dan meninggalkan apa yang kurang baik. Sesuai dengan prinsip Nahdatul Ulama (NU) "melestarikan nilai-nilai lama yang positif dan mengambil nilai-nilai baru yang positif. Prinsipprinsip inilah yang mampu membuat sistem pendidikan pesantren di era modern ini masih tetap eksis.

Legitimasi sebagai tokoh pendidikan, beliau tasbihkan dengan menulis kitab. Salah satu kitab yang menembus batas beliau yakni kitab adab al-'alim wa al-muta'alim. Kitab ini berisi seputar 
materi pembelajaran akhlak. Untuk itu dalam penelitian ini akan di kupas materi pembelajaran akhlak dalam kitab tersebut, yang dapat di jadikan pegangan dalam mengarungi kehidupan. Terutama dalam menyiapkan tantangan pembelajaran Abad 21.

\section{METODE}

Penelitian ini bersifat pustaka (library research). Dalam library research ini peneliti menganalisis isi adab al-'alim wa al-muta'alim. Dalam hal ini peneliti memanfaatkan riset pustaka yang mana tidak sekedar membaca dan mencatat literatur yang telah ada, tetapi juga melakukan penelitian dan mengolah data yang berkenaan dengan materi ajar akhlak siswa dan guru.

Prosedur dalam penelitian ini, peniliti akan menelaah kitab adab al-'alim wa almuta'alim. Sementara data dalam penelitian ini bersifat deskriptif-kualitatif, diperoleh dari hasil telaah sumber data primer yakni adab al-'alim wa al-muta'alim. Hal ini dilakukan guna memperoleh data yang benar-benar valid dan sekaligus memenuhi cakupan serta kedalaman data.

Teknik pengumpulan data dari penilitian ini yaitu teknik dokumentasi, merupakan teknik pengumpulan data yang yang dapat diperoleh dari selain manusia. (Irawan,2008:70), dengan teknik ini akan diperoleh data bersifat deskriptif-kualitatif. Dimana data ini dikumpulkan dengan menelaah adab al-'alim wa al-muta'alim.

Teknik Analisis Data dalam penelitian ini ditujukan untuk menentukan fokus penelitian, apa yang harus digali dan memastikan keabsahan. (Nusa,2013:35) Adapun metode yang digunakan dalam menganalisis data adalah Metode Deskriptif. Tujuan metode analisis data ini adalah mendeskripsikan adab al-'alim wa al-muta'alim. Setelah dideskripsikan selajutnya adalah Analisis Isi. Analisis isi merupakan penelitian yang membahas isi dari sesuatu secara mendalam, baik itu berupa bahan yang tertulis atau pun bahan yang diucapkan. (Irawan,2008:72). Metode analisis isi ini digunakan untuk menganalisa isi yang terdapat dalam adab al-'alim wa al-muta'alim. Selain itu, metode ini digunakan untuk memfokuskan penelitian pada bahan yang tersurat dan tersirat dari isi teks dalam buku tersebut. (Eriyanto,2011:1) Metode analisis isi inilah yang nanti akan digunakan menganalisis

\section{HASIL DAN PEMBAHASAN}

\section{A. Biografi K.H. Hasyim Asy"ari}

K.H. Hasyim Asy'ari memiliki nama lengkap Muhammad hasyim bin asyari bin Abdul wahid bin abdul Halim (pangeran Benawa) bin Abdur Rahman (Jaka Tingkir, sultan Hadi Wijaya) bin Abdullah bin Abdul Aziz bin Abdul Fatah bin Maulana Ishaq (ayah kandung R Ainul Yakin, atau yang lebih mashur dengan sebutan Sunan Giri). 
K.H. Hasyim Asyari lahir pada hari Selasa, 24 Dzulqa'dah 1287 H/14 Februari 1871 M di Gedang, yang terletak di sebelah utara Jombang (Jawa Timur). Dimasa kecil, ia tumbuh dalam didikan ayahnya sendiri, kyai Asyari. Kepada sang ayah, Hasyim Asy'ari banyak balajar membaca al-quran dan beberapa kitab keagamaan. Hingga menginjak remaja, Hasyim Asy'ari dikirim oleh orang tuanya untuk belajar ke berbagai pondok pesantren terkenal di pulau Jawa. Pondok pesantren Sono dan Sewulan di Sidoarjo, Pondok pesantren langitan di Tuban, dan pondok pesantren bangkalan di Madura, asuhan syeh Khalil waliyullah merupakan pondokpondok yang pernah disinggahi K.H. Hasyim Asyari. Selesai menimba ilmu pengetahuan di pondok pesantren Bangkalan Madura, K.H. Hasyim Asyari masih haus akan ilmu. Kemudian ia melanjutkan studi ke tanah suci Makkah dan menetap beberapa tahun di sana. Di kota suci tersebut K.H. Hasyim Asyari berguru kepada beberapa ulama' besar saat itu, diantaranya ia berguru kepada syeh Muahmmad Nawawi bin Umar Banten, syeh Khotib Minangkabau, syeh Suaib bin Abdurrahman, Sayyid Abbas al-Maliki al-Hasany (kepada beliau banyak mengkaji Ilmu-ilmu Hadits), dan kepada syeh Mahfud bin Abdullah Termas (kepada beliau mendalami ilmu-ilmu syariat (fiqih), ilmu alat (nahwu/sharaf),Ilmu adab (sastra),dan beberapa ajian Islam kontemporer). (Muhamad rifai:2010:71)

Sepulang dari Makkah, tepatnya pada tanggal 26 Rabiul Awwal 1317 H/ 1899 M beliau mendirikan pondok pesantren Tebuireng dan madrasah Salafiyah Syafiiyah. Pada pondok inilah beliau langsung menjadi pengajarnya. Cara mengajaranya beliau tekuni dan secara telaten menggembleng dan mendidik para murid / santri yang datang dari berbagai penjuru tanah air demi menimba ilmu pengetahuan.

Kemudian pada tanggal 16 Rajab 1344 H / 31 Januari 1926 M, bersama KH. Abdul Wahab Hasbullah, KH. Bisri Syamsuri, dan beberapa ulama berpengaruh lainya, beliau mendirikan organisasi Nahdlatul Ulama (NU-kebangkitan para Ulama), tujuan utama mendirikan organisasi tersebut adalah untuk mengajak umat Islam Indonesia untuk kembali kepada ajaran Al-quran dan Al-Hadits dalam setiap aspek kehidupan mereka. Selain itu organisasi ini mengajak untuk meninggalkan ajaran sesat dan mengajak mereka untuk berjuang mengagungkan kalimat Allah.

Pada tanggal 7 Ramadhan 1366 H / 1947 M Hasyim Asyari meninggal dunia. Jenazahnya dikebumikan di Pondok Pesantren Tebuireng Jombang Jawa Timur. (Mohammad Kholil:2007:xi)

\section{B. Urgensi Pemikiran K.H. Hasyim Asy'ari}

Ilmu adalah cahaya. Bagi K.H. Hasyim Asy'ari hal yang membedakan manusia dengan binatang adalah ilmunya. Oleh karena itu mencari ilmu bagi seorang manusia sangatlah penting. Di dalam karyanya monumentalnya yakni, adab al-'alim wa al-muta'alim, K.H. Hasyim 
Asy'ari menyebutkan bahwa pendidikan itu penting. Ia berpandangan dengan ilmu dapat menjadi sarana untuk mencapai kemanusiaanya, sehingga manusia sadar siapa sesungguhnya penciptanya, untuk apa diciptakan, melakukan segala hal perintahnya dan menjauhi segala laranganya, untuk berbuat baik didunia dengan menegakkan keadilan. Sehingga layak disebut makhluk yang lebih mulia di banding makhluk-makhluk lain yang diciptakan Allah SWT.

Menurut K.H Hasyim Asy'ari, tujuan diberikannya sebuah ilmu pada setiap manusia, yaitu:

1. Menjadi manusia yang bertujuan untuk mendekatkan diri kepada Allhah Swt.

2. Menjadi manusia yang bertujuan mendapatkan kebahagiaan dunia dan akhirat. (Aly As'ad: 2007: 4-5)

Beliau juga membagi ilmu pengetahuan itu menjadi tiga bagian yaitu:

1. Ilmu pengetahuan yang tercela dan juga dilarang, yaitu; ilmu pengetahuan yang tidak memiliki nilai guna, baik didunia maupun diakhirat.

Contoh: ilmu sihir, nujum dan ramalan nasib

2. Ilmu pengetahuan yang dalam keadaan tertentu menjadi terpuji, tetapi jika mendalaminya menjadi tercela. Ilmu yang dimaksud adalah ilmu yang sekiranya didalami akan menimbulkan kekacauan pikiran, sehingga dikhawatirkan menjadi kufur.

Contoh: ilmu kepercayaan, ilmu kebatinan, ilmu filsafat

3. Ilmu pengetahuan yang terpuji, yaitu; ilmu pelajaran agama dan berbagai macam ibadah, dan dapat menyucikan jiwa pencari ilmu, serta menjauhkan hal tercela, mendekatkan diri kepada Allah Swt dan mempersiapkan dunia ini untuk kepentingan akhirat. (Aly As'ad: 2007: 12-13)

Didalam salah satu kitabnya, adab al-'alim wa al-muta'alim beliau lebih banyak membahas tentang masalah pendidikan yang menekankan pada masalah pendidikan etika/akhlak dan inti penting dari pemikirannya dalam pendidikan adalah "beribadah kepada Allah Swt". Oleh karena itu dalam kitab tersebut yang terdiri dari delapan bab menyebutkan bahwa bagaimana nilai etis dan moral harus menjadi desain besar/latar belakang orang hidup didunia. Dari kitab tersebut terdapat signifikasi pendidikan, tugas dan tanggung jawab seorang murid, serta tugas dan tanggung jawab seorang guru. Dan ketiga pembahasan tersebut akan dijelaskan sebagai berikut:

1. Signifikasi Materi Pendidikan K.H. Hasyim Asy’ari

Dalam membahas hal ini, beliau banyak mengutip Al-Qur'an yang menjelaskan keutamaan ilmu dan dan orang ahli ilmu. Beliau menyebutkan bahwa tujuan utama ilmu pengetahuan adalah mengamalkannya, sehingga ilmu yang dimiliki menghasilkan manfaat dan 
sebagai bekal untuk kehidupan di akherat kelak, karena ilmu yang bermanfaat akan menjadi amal jariyah yang tak akan pernah habis memberikan pahala.

Terdapat dua hal yang harus diperhatikan dalam menuntut ilmu, yaitu:

a. Bagi murid baiknya berniat suci untuk menuntut ilmu, jangan sekali-kali berniat untuk hal-hal duniawi dan jangan melecehkkan dan menyepelekan ilmu

b. Bagi guru dalam mengajarkan ilmu baiknya meluruskan niatanya terlebih dahulu, jangan mengharapkan materi semata. Dan baiknya materi yang diajarkan sesuai dengan tindakan-tindakan yang diperbuat. Oleh karena itu belajar harus diniatkan dan dikembangkan sesuai nilai agama islam, tidak hanya sekedar menghilangkan kebodohan. Jadi berdasarkan kitab adab al-'alim wa al-muta'alim materi pokok nya adalah keseimbangan antara dunia dan akhirat, serta dalam rangka mendekatkan diri kepada Allah. (Aly As'ad: 2007: 17-19) Jika digambarkan sebagai berikut:

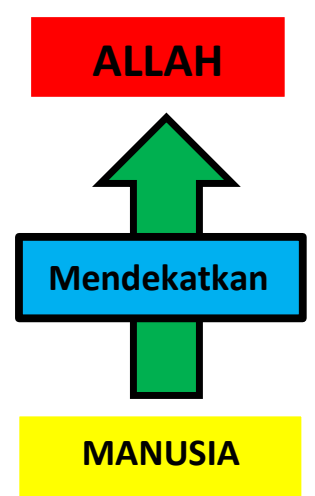

Gambar 1.1. Materi pokok pembelajaran etika/akhlak K.H Hasyim Asy'ari

2. Materi tugas dan tanggung jawab murid

Dalam materi ini dijelaskan tentang etika atau akhlak yang harus dimiliki seorang siswa. Dalam kitab adab al-'alim wa al-muta'alim dijelaskan bahwa ada beberapa materi dasar tentang etika atau akhlak dalam pendidikan. Diantaranya yaitu etika atau akhlak dalam belajar, etika atau akhlak pada guru, etika atau akhlak pada pelajaran. Berikut kami sajikan materi dasar etika/akhlak ketiganya:

Tabel 1.1 Materi Dasar Etika/Akhlak siswa (Aly As'ad: 2007: 35-48)

\begin{tabular}{|l|l|}
\hline No. & \multicolumn{1}{|c|}{ Etika Dalam Belajar } \\
\hline 1. & Membersihkan hati dari berbagai gangguan keimanan dan keduniaan \\
\hline 2. & Membersihkan niat \\
\hline 3. & Tidak menunda-nunda kesempatan belajar \\
\hline 4. & Bersabar dan qanaah \\
\hline 5. & Pandai mengatur waktu \\
\hline 6. & Menyederhanakan makan dan minum \\
\hline
\end{tabular}




\begin{tabular}{|l|l|}
\hline 7. & Bersikap berhati-hati (wara') \\
\hline 8. & $\begin{array}{l}\text { Menghindari makanan dan minuman yang menyebabkan kemalasan yang } \\
\text { kemudian menimbulkan kebodohan }\end{array}$ \\
\hline 9. & Menyedikitkan waktu tidur selagi tidak merusak kesehatan \\
\hline 10 & Meninggalkan hal-hal yang kurang berfaedah. \\
\hline
\end{tabular}

Dalam tabel terlihat bahwa K.H. Hasyim Asy'ari lebih menekankan pada pendidikan ruhani (batin) atau pendidikan jiwa. Meskipun pendidikan jasmani tetap diperhatikan, khususnya bagaimana manajemen waktu, majemen makan dan minum dan sebagainya. Pemikiran beliau sangat bernuansa kesederhanaan dan pokok pemikirannya adalah menciptakan ruh manusia yang produktif dan dinamis pada jalan yang benar.

Selanjutnya adalah untuk melihat urgensi materi ajar akhlak dari K.H.Hasyim As'ari dengan pembelajaran abad 21 dapat terlihat dalam materi ajar etika atau akhlak pada guru. Berikut uraian materinya:

Tabel 2.1 Materi dasar etika atau akhlak pada guru (Aly As'ad: 2007: 35-48)

\begin{tabular}{|l|l|}
\hline No. & \multicolumn{1}{|c|}{ Etika Murid pada Guru } \\
\hline 1. & Hendaknya selalu memperhatikan dan mendengarkan guru \\
\hline 2. & Memilih guru yang wara' \\
\hline 3. & Mengikuti jejak guru \\
\hline 4. & Memuliakan guru \\
\hline 5. & Memperhatikan apa yang menjadi hak guru \\
\hline 6. & Bersabar terhadap tindakan disiplin (kekerasan) guru \\
\hline 7. & Berkunjung pada guru pada tempatnya dan minta izin lebih dulu \\
\hline 8. & Duduk dengan rapi dan sopan jika berhadapan dengan guru \\
\hline 9. & Berbicara secara sopan dan lembut pada guru \\
\hline 10. & Dengarkan segala fatwa guru \\
\hline 11. & Jangan menyela pembicaraannya \\
\hline 12. & Gunakan tangan kanan bila menyerahkan sesuatu pada guru. \\
\hline
\end{tabular}

Berdasar tabel diatas, terlihat etika masih sering ditemukan pada pendidikan pesantren. Konsep yang ditawarkan K.H. Hasyim Asy'ari masih sangat relevan. Adanya masalah yang kian komplek, namun tidak menghalangi pemikiran yang ditawarkan oleh K.H. Hasyim Asy'ari. Pemikiran beliau justru terlihat lebih maju. Hal ini, terlihat dalam etika berbicara sopan dan lembut pada guru. Hari ini dijaman serba dugital, banyak sekali siswa yang cenderung 
berkomunikasi dengan guru tidak dengan etika. Hasilnya budaya sopan santun, mengahrgai yang lebih tua mulai pudar.

Selanjutnya adalah urgensi materi ajar akhlak dari K.H. Hasyim Asy'ari dengan pembelajaran abad 21 dapat terlihat dalam materi ajar etika atau akhlak pada mata pelajaran. Berikut uraian materinya:

Tabel 3.1 Materi dasar etika atau akhlak pada mata pelajaran (Aly As'ad: 2007: 35-48)

\begin{tabular}{|l|l|}
\hline No. & \multicolumn{1}{|c|}{ Etika seorang murid pada pelajaran } \\
\hline 1. & Memperhatikan ilmu yang fardhu 'ain \\
\hline 2. & Harus mempelajari ilmu-ilmu yang mendukung ilmu fardhu ain \\
\hline 3. & Waspada dalam menanggapi ikhtilaf para ulama \\
\hline 4. & Mendiskusikan dan menyerahkan hasil belajar pada orang yang dipercaya \\
\hline 5. & Senantiasa menganalisa dan memperhatikan ilmu \\
\hline 6. & Miliki cita-cita yang tinggi \\
\hline 7. & Bergaulah dengan orang yang berilmu lebih tinggi (pintar) \\
\hline 8. & Ucapkan salam ketika sampai di tempat majlis ta'lim (sekolah/madrasah) \\
\hline 9. & Jika terdapat hal-hal yang belum dipahami hendaklah ditanyakan \\
\hline 10. & Jika kebetulan bersamaan dengan banyak teman maka sebaiknya jangan \\
& mendahului antrian kalau tidak mendapatkan izin \\
\hline 11. & Kemanapun pergi dan dimanapun berada jangan lupa membawa catatan \\
\hline 12. & Pelajari pelajaran yang telah dipelajari dengan continue (istiqamah) \\
\hline 13. & Miliki rasa antusias dalam belajar. \\
\hline
\end{tabular}

Penjelasan di atas seakan memperlihatkan sistem pendidikan di pesantren yang terlihat kolot. Seolah-olah guru satu-satunya sumber pengajaran, dan murid hanya sebagai obyek yang duduk, mendengar, mencatat dan menghafal apa yang dititahkan guru. Namun, perlu disadari bahwa pemikiran K.H. Hasyim Asy'ari lebih open minded, inovatif dan progresif. K.H.Hasyim Asy'ari memberikan kesempatan pada santri untuk belajar kepada ulama yang berilmu tinggi. Tapi beliau memberi rambu-rambu agar waspada dalam menanggapi ikhtilaf para ulama.

Tamabahan juga bahwa dalam membahas tentang ilmu yang wajib dipelajari, K.H. Hasyim Asy'ari memiliki gagasan yang sejalan dengan pemikiran al-ghazali, yakni:

a. Fardhu 'ain: kewajiban mencari ilmu dibebankan kepada stiap muslim

b. Fardhu kifayah: ilmu yan di perlukan dalam rangka menegakkan urusan duniawi. (Muhammad Rifai:2007;77)

3. Materi tugas dan tanggung jawab Guru 
Dalam materi ini dijelaskan tentang etika atau akhlak yang harus dimiliki seorang guru. Dalam kitab adab al-'alim wa al-muta'alim dijelaskan bahwa ada beberapa materi dasar tentang etika atau akhlak yang harus ada pada guru. Diantaranya yaitu etika atau akhlak seorang guru, etika atau akhlak guru dalam mengajar, etika atau akhlak dalam mengajar, etika atau akhlak kepada murid, etika atau akhlak guru pada buku dan media pembelajaran. Berikut kami sajikan materi dasar etika/akhlak keempatnya:

Tabel 1.4 Materi Dasar Etika/Akhlak guru (Aly As'ad: 2007: 95-99)

\begin{tabular}{|l|l|}
\hline No. & \multicolumn{1}{|c|}{ Etika/ akhlak guru } \\
\hline 1. & Selalu mendekatkan diri pada Allah \\
\hline 2. & Selalu takut pada Allah, tawadhu', dan khusu' \\
\hline 3. & Bersikap tenang dan selalu berhati-hati \\
\hline 4. & Mengadukan segala persoalan pada Allah \\
\hline 5. & Tidak menggunakan ilmunya untuk meraih dunia saja \\
\hline 6. & Tidak memanjakan anak \\
\hline 7. & Berlaku zuhud dalam kehidupan dunia \\
\hline 8. & Menghindari tempat-tempat yang kotor dan maksiat \\
\hline 9. & Mengamalkan sunnah Nabi \\
\hline 10. & Mengistiqamahkan membaca al- Qur'an \\
\hline 11. & Bersikap ramah, ceria dan suka menebar salam \\
\hline 12. & Membersihkan diri dari perbuatan-perbuatan yang tidak disukai Allah \\
\hline 13. & Menumbuhkan semangat untuk menambah ilmu \\
\hline 14. & Tidak menyalahgunakan ilmu dengan cara menyombongkannya \\
\hline 15. & Membiasakan diri dengan menulis, membuat karangan dan meringkas \\
\hline
\end{tabular}

Berdasarkan tabel diatas K.H. Hasyim Asy'ari memencontohkan kepada para pendidik untuk menjadikan ilmu sebagai sarana untuk memperoleh kepada akhirat. Jangan menuntut gaji semata dari mendidik, tapi guru harus ikhlas dan dan berlaku zuhud kepada dunia. Dan juga anjuran beliau yang relevan hingga hari ini adalah tentang guru yang harus membiasakan diri untuk menulis, mengarang dan membuat ringkasan/resume. Di era seperti ini menulis bagi guru adalah kewajiban, agar ilmu bisa selalu dinamis dan berkembang. Dan hal ini beliau buktikan dengan banyaknya kitab hasil karangan atau tulisan beliau. (Samsul Nizar: 2002: 155162)

Selanjutnya adalah urgensi materi ajar akhlak dari K.H.Hasyim As'ari dengan pembelajaran abad 21 dapat terlihat dalam materi ajar etika atau akhlak guru dalam mengajar. Berikut uraian materinya 
Tabel 1.5 Materi Dasar Etika/Akhlak guru (Aly As'ad: 2007: 119-120)

\begin{tabular}{|l|l|}
\hline No. & \multicolumn{1}{|c|}{ Etika/akhlak seorang guru dalam mengajar } \\
\hline 1. & Mensucikan diri dari segala hadas sebelum masuk majelis. \\
\hline 2. & Ketika masuk majelis hendaknya mengucapkan salam. \\
\hline 3. & Menghadapi peserta didik dengan penuh perhatian. \\
\hline 4. & Memulai pelajaran dengan membaca ayat-ayat al-quran. \\
\hline 5. & Memulai dengan materi-materi yang penting \\
\hline 6. & Mengatur volume suara atau intonasi. \\
\hline 7. & Menjaga majelis dari ke gaduhan \\
\hline 8. & Mengingatkan siswa untuk menjaga persaudaraan. \\
\hline 9. & $\begin{array}{l}\text { Memberi peringatan tegas ketika siswa menyimpang dari etika yang } \\
\text { semestinya. }\end{array}$ \\
\hline 10. & Mengakui ketidak tahuannya terhadap suatu hal. \\
\hline 11. & $\begin{array}{l}\text { Menyebut dan menyertakan asma Allah baik ketika membuka ataupun } \\
\text { menutup. }\end{array}$ \\
\hline 12. & Mengajar secara professional sesuai bidang keahliannya. \\
\hline
\end{tabular}

Pemikiran K.H. Hasyim Asy'ari sangat fenomenal, beliau kurang lebih menekankan pada etika guru untuk menjadi seorang yang menginspirasi atau tauladan bagi perilaku peserta didik. Sehingga proses pembelajaran lebih kondusif dan menyegarkan.

Kemudian urgensi dalam pembelajaran abad 21 dari pemikiran K.H. Hasyim Asy'ari juga terlihat pada etika guru bersama murid, berikut uraian materinya:

Tabel 1.6 Materi Dasar Etika/Akhlak guru kepada murid (Aly As'ad: 2007: 121-122)

\begin{tabular}{|l|l|}
\hline No. & \multicolumn{1}{|c|}{ Etika seorang guru kepada murid } \\
\hline 1. & $\begin{array}{l}\text { Memberikan pengajaran dan pendidikan kepada siswa dengan niat serta } \\
\text { tujuan yang luhur. }\end{array}$ \\
\hline 2. & $\begin{array}{l}\text { Selalu besabar dan tidak menyurutkan semangatnya dalam memberikan } \\
\text { pengajaran. }\end{array}$ \\
\hline 3. & Mencintai para siswa sebagaimana ia mencintai dirinya \\
\hline 4. & $\begin{array}{l}\text { Mendidik dan memberi pelajaran dengan penjelasan atau metode yang mudah } \\
\text { di pahami }\end{array}$ \\
\hline 5. & $\begin{array}{l}\text { Bersungguh- sungguh dalam memberikan pengajaran dan memahamkan } \\
\text { siswa. }\end{array}$ \\
\hline
\end{tabular}




\begin{tabular}{|l|l|}
\hline 6. & Memberikan waktu pada siswa untuk mereview pelajaran \\
\hline 7. & Tidak memberikan materi yang terlalu banyak. \\
\hline 8. & Tidak memberikan perlakuan khusus pada seorang siswa. \\
\hline 9. & Memberikan kasih sayang dan perhatian pada siswa. \\
\hline 10. & Selalu memberikan contoh kepada siswa tentang cara bergaul yang baik. \\
\hline 11. & Turut membantu dan meringankan masalah siswa. \\
\hline 12. & $\begin{array}{l}\text { Memperhatikan siswa agar menjadi seorang insan yang sholeh dan } \\
\text { bermanfaat bagi orang lain. }\end{array}$ \\
\hline 13. & Selalu bersikap tawadlu' dan rendah hati. \\
\hline 14. & Memperlakukan siswa dengan baik \\
\hline
\end{tabular}

Berdasar analisis isi dalam tabel diatas K.H. Hasyim Asy'ari sangat menganjurkan agar seorang pendidik bisa memiliki inisiatif dan inovasi dalam menyampaikan pembelajaran. Dan menganjurkan kepada para guru untuk berlaku adil dan bijaskana kepada setiap individu murid. Tentunya semua itu di dasarkan atas niat dan tujuan yang luhur.

Didalam buku yang ditulis Muhamad Rifai, salah satu metode K.H. Hasyim Asy'ari yang hasilnya sangat cemerlang yaitu menggunakan metode musyawarah bagi para santrinya, untuk dijadikan tradisi dalam membahas ilmu-ilmu yang diajarkan oleh ustad/gurunya yang kemudian hari menjadi lajnah bahtsul masa'il sebagai bentuk tradisi intelektual NU atau pesantren. (Muhammad Rifai: 79)

Metode musyawarah berbeda dengan metode debat (munadarah), metode musyawarah ini dikembangkan seperti diskusi antar santri. Dengan metode inilah akan terbangun rasa keterbukaan, toleransi serta memberikan rasa peduli kepada pendapat lawan. Titik capaianya adalah kebenaran dan mengusahakan suatu pemecahan yang terbaik. (Toto Suharto:2013: 339)

Selanjutnya materi etika atau akhlak guru terhadap buku, alat pelajaran dan media pembelajaran, berikut materinya:

Tabel 1.7 Materi Dasar Etika/Akhlak guru kepada buku, alat pelajaran dan media pembelajaran, (Aly As'ad: 2007: 124-125)

\begin{tabular}{|l|l|}
\hline No. & \multicolumn{1}{|c|}{$\begin{array}{c}\text { Etika seorang guru kepada buku, alat pelajaran dan media } \\
\text { pembelajaran }\end{array}$} \\
\hline 1. & Menganjurkan agar memiliki buku \\
\hline 2. & $\begin{array}{l}\text { Merelakan dan mengijinkan jika ada teman yang meminjam buku pelajaran, } \\
\text { sebaliknya bagi peminjam menjaga barang pinjamannya }\end{array}$ \\
\hline 3. & Memeriksa dahulu jika hendak membeli dan meminjamnya \\
\hline
\end{tabular}


\begin{tabular}{|l|l|}
\hline 4. & Bila menyalin buku syari'ah hendaknya bersuci dan mengawalnya dengan
\end{tabular} basmalah, sedangkan bila ilmu retorika atau semacamnya, maka mulailah dengan hamdalah (puji-pujian) dan shalawat Nabi.

Berdasar tabel uraian diatas, bagi K.H. Hasyim Asy'ari memandang bahwa etika guru kepada buku, alat pelajaran dan media pembelajaran penting dan perlu diperhatikan. Dari sini tampak kesadaran beliau tentang pentingnya ilmu. K.H. Hasyim Asy'ari sadar bahwa yang namanya buku/kitab memuat ilmu pengetahuan dan layak untuk dijaga.

Sehingga wajar dalam urgensi pemikiran K.H. Hasyim Asyari menempatkan pembahasan khusus tentang etika terhadap buku. Beliau berpandangan bahwa, ilmu adalah Nur (cahaya) Allah, maka bila hendak mencapi Nur tersebut maka pembelajar harus suci. Baik suci dari hadats besar dan kecil serta suci jiwa atau ruhaninya. Dengan demikian ilmu yang dipelajari diharapkan bermanfaat dan dapat membawa berkah. (Samsul nizar: 2002:167-168)

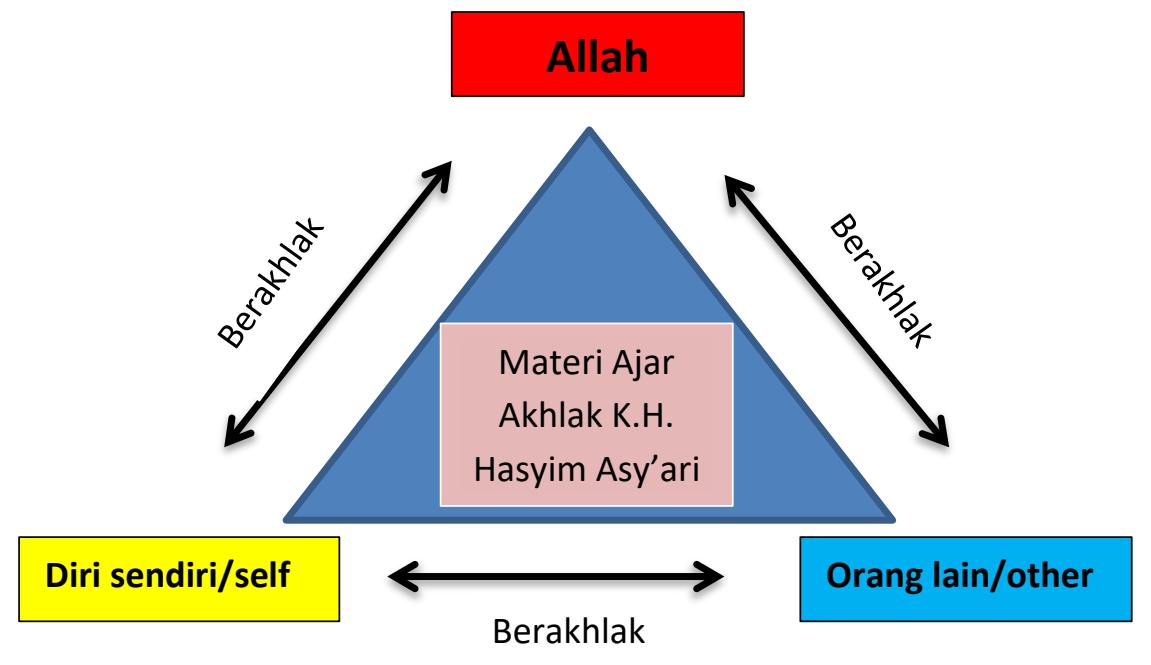

Gambar 1.2. Multiple effect urgensi materi pokok pembelajaran etika/akhlak K.H. Hasyim Asy'ari dalam menyambut pembelajaran abad 21

Materi pembelajaran Akhlak K.H. Hasyim As'ari sangat urgen untuk diterapkan didewasa ini. Adanya materi pembelajaran akhlak tersebut dapat menjadi bekal dalam menyiapkan generasi untuk menghadapi tantangan pembelajaran abad 21 ini. Sehingga pada akhirnya siswa dengan materi ajar etika/akhlak ini dapat dicintai dan dimuliakan oleh orang lain, serta akan dicintai dan diridhoi oleh Allah swt.

Tantangan pada abad pembelajaran Abad 21 ini menuntut siswa-siswa mapu punya skill lebih. Atau bahasa sederhananya multithasking. Akibatanya kalau tidak hati-hati bisa membawa seseorang pada sikap sombong dan angkuh. Untuk itu adanya materi pembelajaran akhlak dari K.H. Hasyim Asy'ari dapat membekali sumber daya manusia memiliki pondasi 
akhlak terpuji. Sehingga setinggi apapun prestasi, kesuksesan, keahlian dan apapun karir SDMnya akan tetap punya itegritas. Urgensi dari materi pembelajaran akhlak dari K.H. Hasyim As'ari, jika digambarkan sebagai berikut:

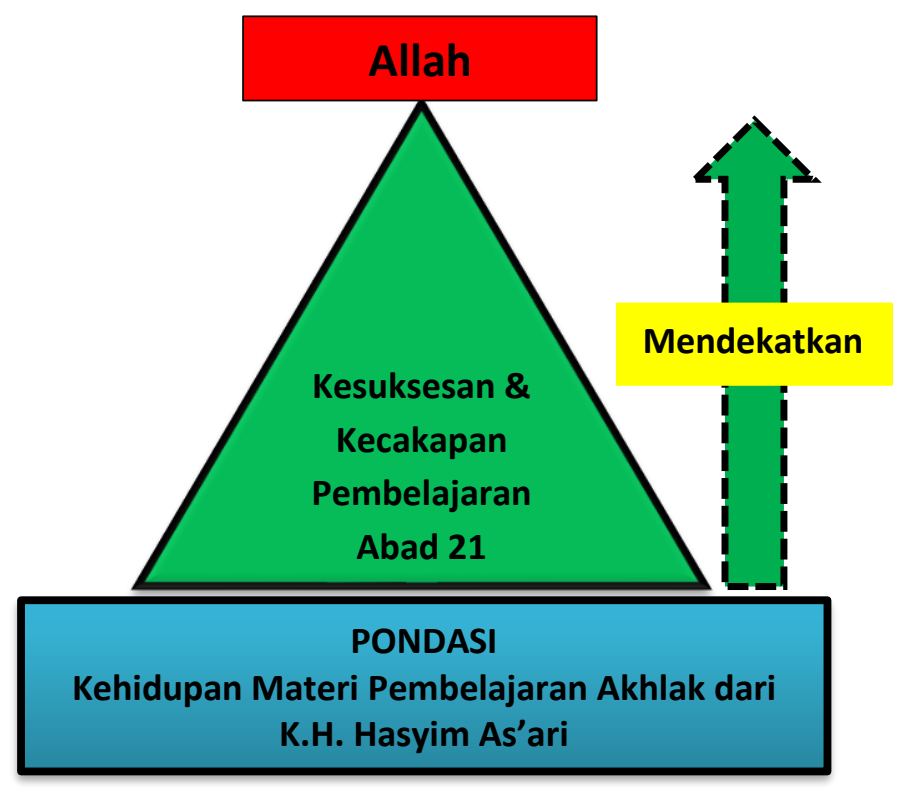

Gambar 1.3. Urgensi materi pokok pembelajaran etika/akhlak K.H. Hasyim Asy'ari dalam menyambut pembelajaran abad 21.

\section{KESIMPULAN}

KH. M. Hasyim Asy'Ari dengan nama lengkapnya adalah Muhammad Hasyim bin Asyari bin Abdul Wahid bin Abdul Halim (pangeran Benawa) bin Abdur Rahman (Jaka Tingkir, Sultan Hadi Wijaya) bin Abdullah bin Abdul Aziz bin Abdul Fatah bin Maulana Ishaq (ayah kandung $\mathrm{R}$ Ainul Yakin, atau yang lebih mashur dengan sebutan sunan giri). Di dalam salah satu karyanya, adab al-'alim wa al-muta'alim, K.H. Hasyim Asy'ari menyebutkan bahwa pendidikan adalah penting. Bagi beliau menuntut ilmu merupakan aktivitas yang luhur, sehingga orang yang mencarinya harus memperlihatkan etika yang luhur pula. Didalam kitabnya tersebut beliau lebih banyak membahas tentang terkait pendidikan yang menekankan pada pendidikan etika/ akhlak. Point penting dari pemikirannya dalam pendidikan adalah "beribadah kepada Allah Swt" atau mendekatkan diri kepada Allah. Sehingga dalam menyambut pembelajaran abad 21 memiliki urgensi materi ajar akhlak beliau memiliki urgensi. Urgensinya terlihat dari materi ajar akhlak K.H. Hasyim Asy'ari dapat membekali akhlak secara multipleeffect (baik kepada diri sendiri, kepada sesama dan kepada Allah). Sehingga adanya materi akhlak tersebut siswa memiliki pondasi integritas dalam berkehidupan sosial dan mengarungi tantangan Abad 21. 


\section{ACKNOWLEDGEMENT}

Penulis adalah salah satu pengajar di Universitas Mercu Buana Yogyakarta. Penulis mengucapkan terimakasih kepada segenap tim redaksi dari Jurnal Scaffolding karena telah membantu terbitnya tulisan ini hingga menjadi karya ilmiah yang terpublikasi. Penulis juga mengucapkan maaf jika terdapat kesalahan dalam tulisan ini, sehingga penulis mempersilahkan untuk pembaca sekalian melakukan kritik yang membangun agar tercipta tulisan yang lebih baik di kemudian hari.

\section{BIBLIOGRAFI}

As'ad, Ali, (2007). Terjemah Ta'lim Muta'alim, Kudus, Menara Kudus.

Asy'ari, K.H. Hasyim, (1994). adab al-'alim wa al-muta'alim, Maktabah At-Turats Al-Islamy, Tebuireng Jombang Jawa Timur.

Ditjen Pendidikan Dasar dan Menengah,( 2017). Panduan implementasi kecakapan abad 21 pada kurikulum 2013 Disekolah Menengah Atas, Jakarta, Dit. PSMA Ditjen Pendidikan Dasar dan Menengah.

Eriyanto, (2011). Analisis Isi, Jakarta: Kencana.

Kholil ,Mohammad, (2007). Etika Pendidikan Islam: Petuah KH. M.Hasyim Asyari, Yogyakarta, Titian Wacana.

Nizar, Samsul, (2002). filsafat pendidikan islam "pendekatan historis, teoritis, dan praktis, Jakarta, ciputat pers.

Nusa Putra dan Santi Lisnawati, (2013). Penelitian Kualitatif Pendidikan agama Islam. Bandung: Remaja Rosdakarya. Peraturan Pemenrintah Nomor 32 Tahun 2013 tentang SNP.

Rifai, Muhamad, (2010). K.H. Hasyim Asy'ari biografi singkat 1871-1947, yogyakarta, GARASI. Suharto,Toto, ( 2013), filsafat pendidikan islam, yogyakarta, Ar-ruzz media.

Suhartono, Irawan. (2008). Metode Penelitian Sosial. Bandung: Remaja Rosdakarya.

Tribun-Medan.com, (2020). siswa-sma-buka-bra-di-instagram-jenuh-banyak-pr-kpai-sebut-inibentuk-kebosanan-belajar-di-rumah, diakses taggal 22 Juni 2020, pukul 08.00 wib. 